\title{
Biochemical indices of response to hydroxychloroquine and sodium aurothiomalate in rheumatoid arthritis
}

\author{
J. S. DIXON, M. E. PICKUP, H. A. BIRD, M. R. LEE, \\ V. WRIGHT, AND W. W. DOWNIE
}

From the Clinical Pharmacology Unit, Royal Bath Hospital, Harrogate, and the University Department of Medicine, General Infirmary, Leeds

SUMMARY Biochemical and clinical changes have been monitored in 30 patients with rheumatoid arthritis treated with either hydroxychloroquine or sodium aurothiomalate over a period of 6 months. Acute-phase reactants improved in both treatment groups, while serum sulphydryl and serum histidine improved only in the gold-treated patients. Correlation matrices were constructed from mean clinical and biochemical data at successive clinic visits. Correlations obtained with gold were more frequent and of a higher level of significance than those obtained with hydroxychloroquine at the doses we studied. This lends support to the use of correlation matrices as a screening test for potential long-term antirheumatoid activity of drugs in man.

In an attempt to define biochemical and clinical changes that occur when patients with rheumatoid arthritis are exposed for the first time to 'specific antirheumatoid' therapy, and to see if these changes differ between drugs we have performed serial biochemical and clinical assessments over the first 6 months of treatment with a series of drugs for which antirheumatoid action has been claimed. Our results for groups of 15 patients treated with Dpenicillamine ${ }^{12}$ and alclofenac ${ }^{2}$ have been described. We have now added 2 further groups of patients treated with hydroxychloroquine sulphate (HCQ) and sodium aurothiomalate (gold) in order to compare possible differences in biochemical response and to consider whether any particular changes are indicative of specific antirheumatoid effect. We have previously suggested that comparison of correlation matrices, constructed between mean data for biochemical and clinical variables, has relevance as a screening test for antirheumatoid activity. ${ }^{2} \mathrm{We}$ have therefore compared similar matrices for HCQ and gold.

\section{Patients and methods}

PATIENTS

Fifteen patients (13 female, mean age $51 \cdot 8$, range

Accepted for publication 6 November 1980

Correspondence to Professor V. Wright, Clinical Pharmacology Unit, Royal Bath Hospital, Cornwall Road, Harrogate HG1 2PS.
39 to 66 years; 2 male, aged 31 and 49 years) were allocated to HCQ therapy, and a further 15 patients (11 female, mean age $52 \cdot 7$, range 36 to 67 years; 4 male, mean age $54 \cdot 5$, range 45 to 64 years) were allocated to gold therapy. All patients had classical or definite RA (American Rheumatism Association criteria) and at least moderate disease activity previously defined ${ }^{12}$ by the presence of at least 3 of the following 5 criteria: (a) tenderness of more than 6 joints; $(b)$ swelling of more than 3 joints; $(c)$ morning stiffness longer than 45 minutes; $(d)$ articular index more than $20 ;(e)$ ESR more than $28 \mathrm{~mm} . \mathrm{h}^{-1}$. None of the patients had received specific antirheumatoid drug therapy (e.g., gold, penicillamine, HCQ) before the present study. Patient exclusions were also as previously described. ${ }^{12}$

DRUG DOSAGE

Over a 24-week period HCQ was given in a dose of $200 \mathrm{mg}$ b.d. and gold in a dose of $50 \mathrm{mg}^{2}$ week $^{-1}$ intramuscularly until $1 \mathrm{~g}$ had been given; then $50 \mathrm{mg}$. month ${ }^{-1}$ irrespective of clinical response.

Both groups received enteric coated aspirin in a dose of $3 \cdot 6 \mathrm{~g}$. day ${ }^{-1}$ in the 2 weeks immediately preceding the study to establish 'baseline' conditions for clinical and systemic variables. During the 24 weeks of the study patients took supplementary enteric coated aspirin as required. However, 1 patient in each group took dextropropoxyphene and paracetamol tablets (Distalgesic) in place of aspirin 
HYDROXYCHLOROQUINE
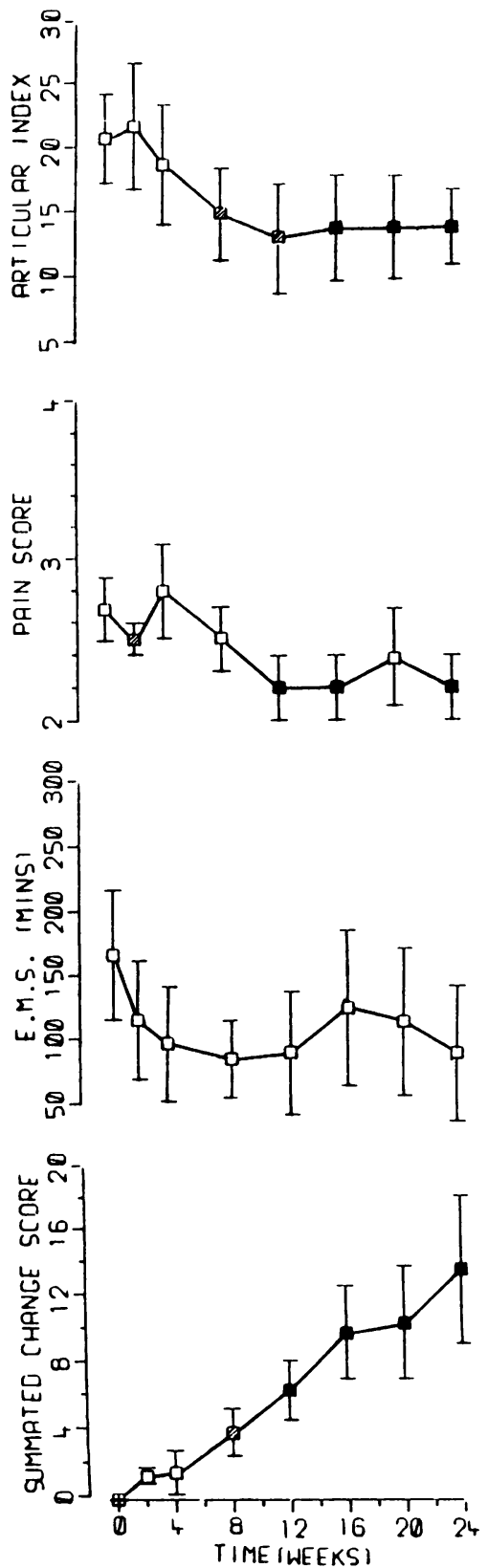

GOLD
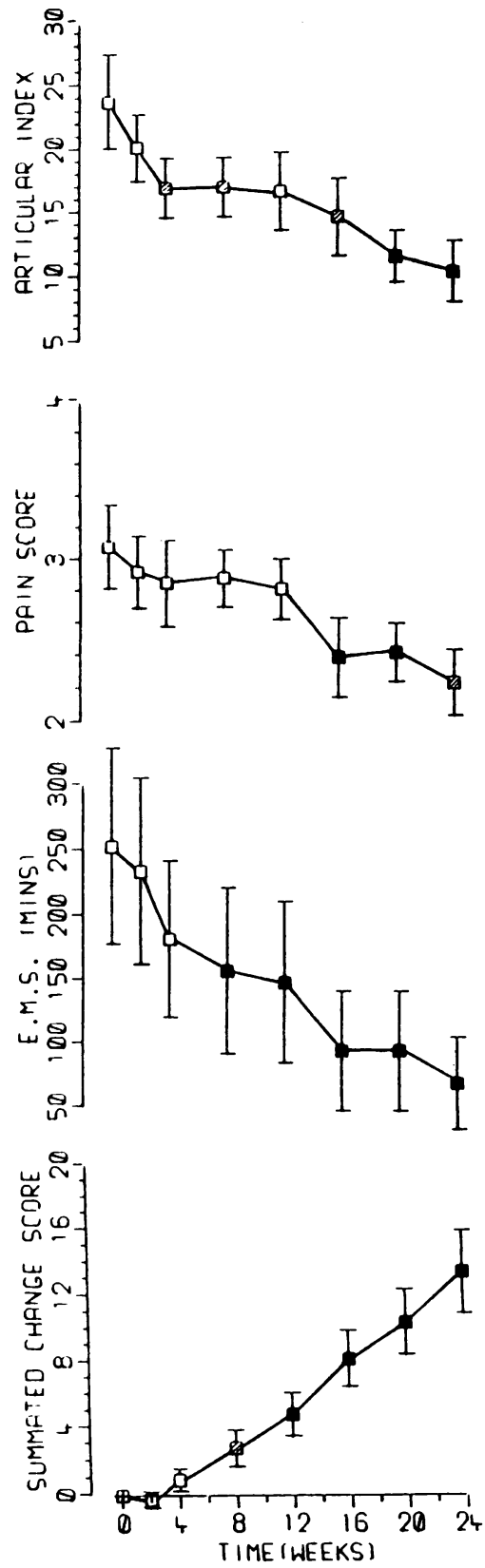

Fig. 1 Clinical data (mean $\pm S E$ ) for rheumatoid patients treated with hydroxychloroquine (left) and sodium aurothiomalate (right). Changes in individual parameters reaching statistical significance (Wilcoxon rank sum test) when compared with data at week 0 are indicated by hatched $(p<0.05)$ and closed $(p<0.01)$ data points. 
HYDROXYCHLOROQUINE
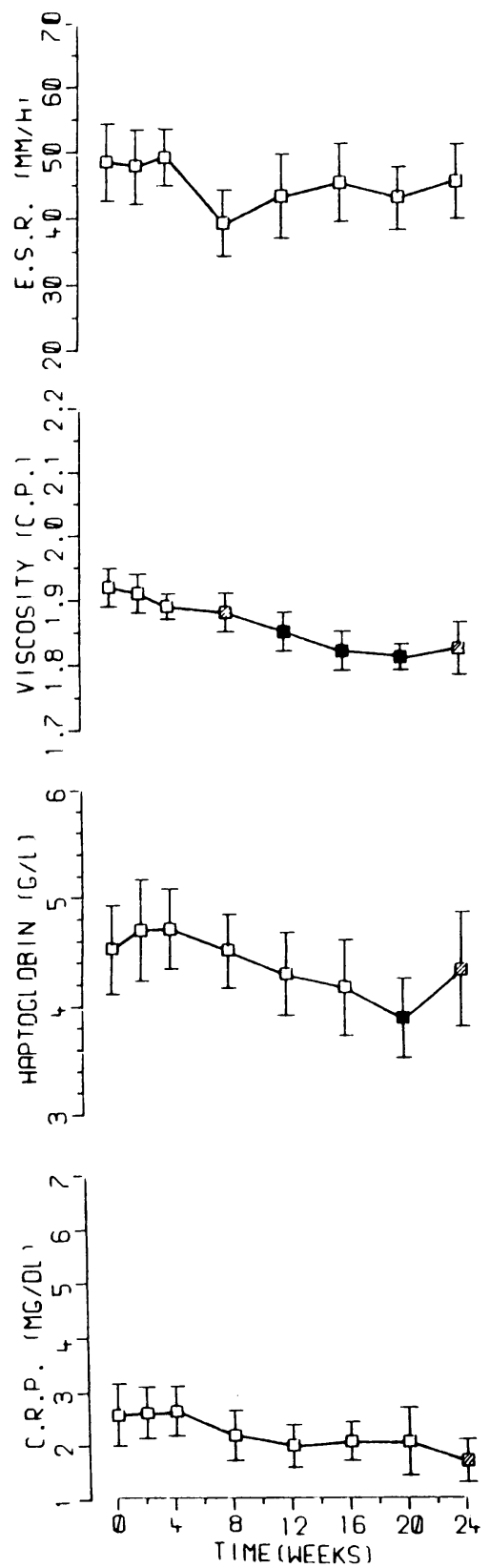

GOLD
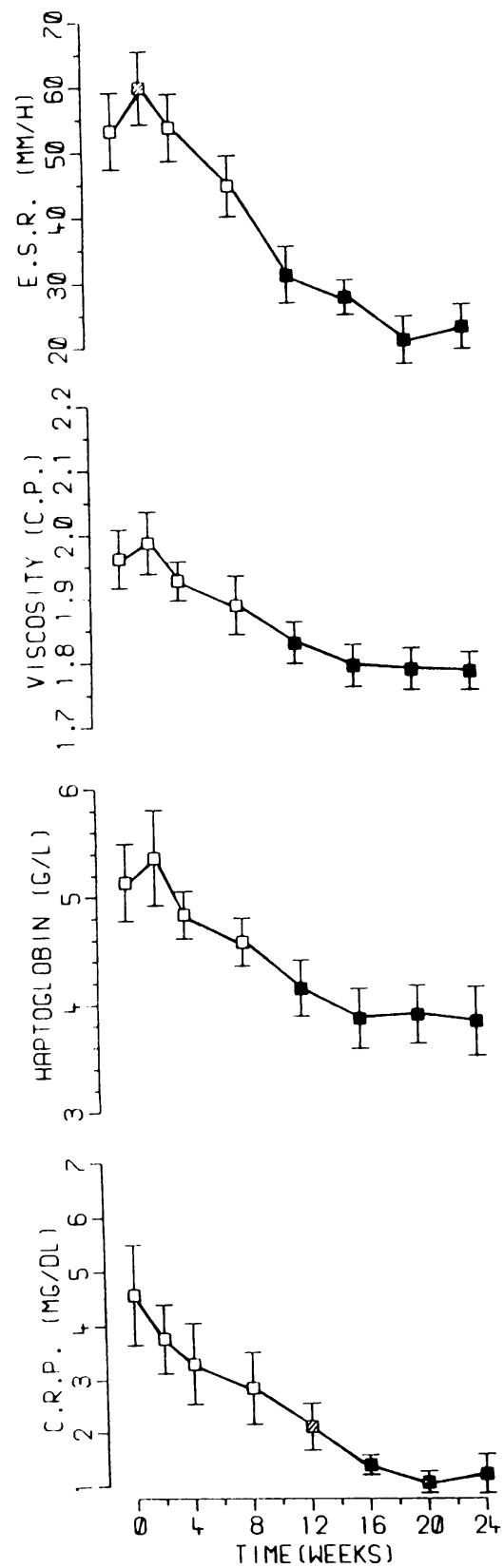

$2 \mathrm{~A}$

Figs. 2 A, B, C Biochemical data (mean $\pm S E$ ) for rheumatoid patients treated with hydroxychloroquine (left) and sodium aurothiomalate (right). Changes in individual parameters reaching statistical significance (Wilcoxon rank sum test $)$ when compared with data at week 0 are indicated by hatched $(p<0.05)$ and closed $(p<0.01)$ data points. 

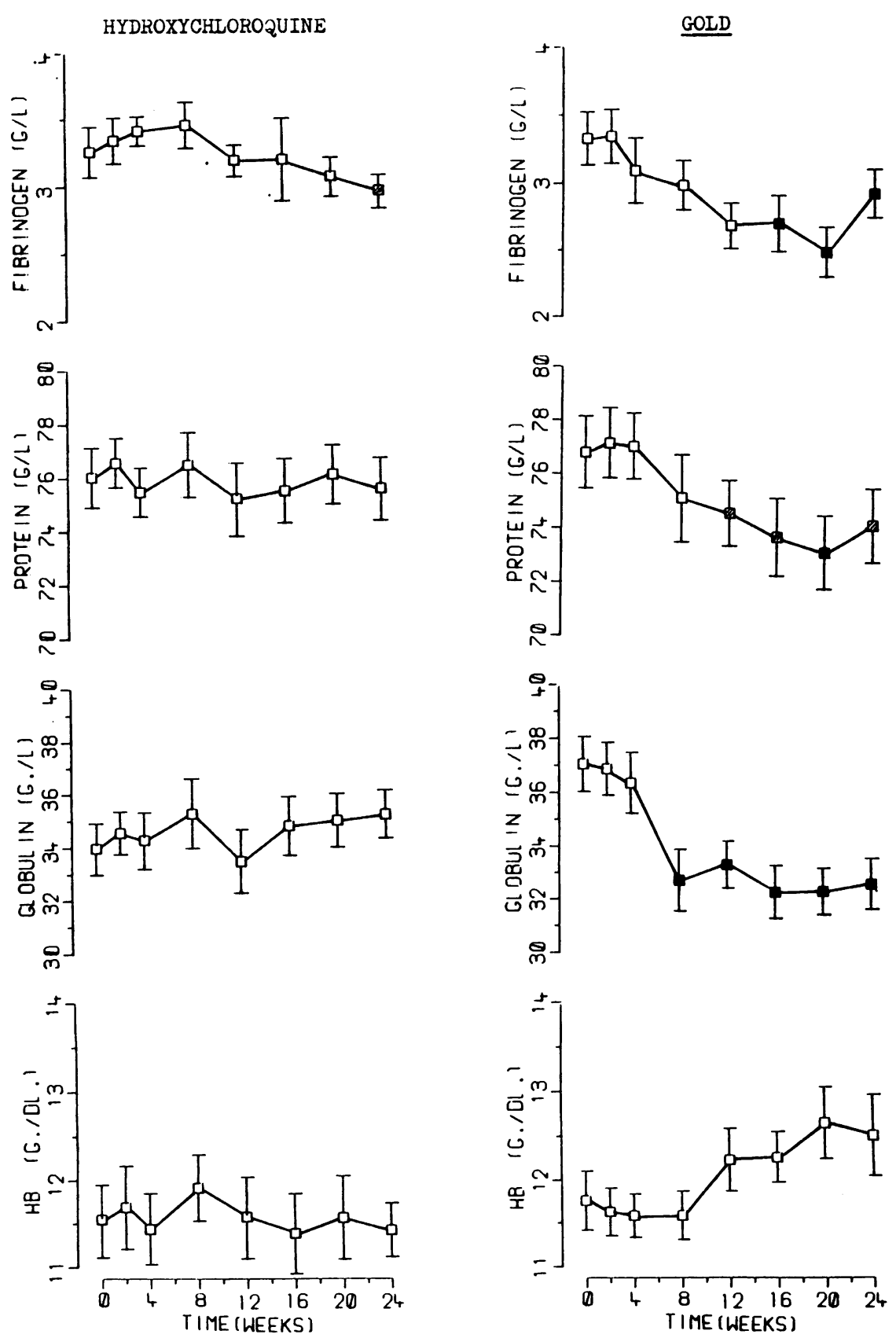
owing to aspirin intolerance. No other drugs were allowed except prednisolone therapy in constant dosage (maximum $7.5 \mathrm{mg}$.daily) for 2 patients in each drug group.

\section{ASSESSMENT PROCEDURES}

Patients were seen at weeks $-2,0,2,4,8,12,16,20$, and $24(0=$ date of starting specific antirheumatoid drug therapy). At each visit 18 biochemical and 8 clinical assessments were made as previously described. ${ }^{2} 2$

In view of the reported retinopathy associated with chloroquine and HCQ therapy ${ }^{3-5}$ routine ophthalmological tests were performed on the 15 HCQ-treated patients.

All patients completed the 24-week treatment period, irrespective of clinical response, though 2 patients on hydroxychloroquine who failed to attend after week 4 were not replaced.

\section{STATISTICAL METHODS}

To test for significant changes in individual clinical or laboratory variables over the 24-week treatment period week 0 data were compared in turn with data from successive clinic visits by the Wilcoxon matched pairs signed rank test for paired data. ${ }^{6}$ One-way analysis of variance was used to test for any differences between week $\mathbf{0}$ data for each variable in the 2 drug groups. Correlation matrices were constructed between clinical and laboratory variables for both HCQ and gold in turn. Each laboratory variable was correlated (Pearson correlation) in turn with each clinical variable; mean data obtained from each of the 8 clinic visits from the start of specific therapy were used. ${ }^{2}$

\section{Results}

HYDROXYCHLOROQUINE THERAPY

Of the 13 patients completing 24 weeks' treatment

Table 1 Correlation matrices for $(A)$ hydroxychloroquine and $(B)$ sodium aurothiomalate. Figures shown represent the significance $(p<)$ of Pearson correlations $(r)$ between mean clinical and mean biochemical variables at successive clinic visits $(n=8)$. Biochemical variables are arranged so that those showing highly significant correlations with clinical variables are placed towards the top

\begin{tabular}{|c|c|c|c|c|c|c|c|c|}
\hline & $\begin{array}{l}\text { Articular } \\
\text { index }\end{array}$ & Joint size & $\begin{array}{l}\text { Summated } \\
\text { change } \\
\text { score }\end{array}$ & $\begin{array}{l}\text { Aspirin } \\
\text { dose }\end{array}$ & $\begin{array}{l}\text { Early } \\
\text { morning } \\
\text { stiffness }\end{array}$ & $\begin{array}{l}\text { Grip } \\
\text { strength }\end{array}$ & Pain score & $\begin{array}{l}\text { Functional } \\
\text { grade }\end{array}$ \\
\hline \multicolumn{9}{|l|}{ A. Hydroxychloroquine } \\
\hline CRP & 0.01 & 0.01 & 0.001 & - & - & - & 0.01 & 0.05 \\
\hline Alkaline phosphatase & 0.05 & 0.01 & 0.05 & 0.001 & 0.01 & - & - & - \\
\hline Plasma viscosity & 0.01 & 0.001 & 0.001 & - & - & 一 & 0.05 & - \\
\hline ESR & 0.01 & 0.05 & - & - & - & - & 0.05 & - \\
\hline Albumin & 0.05 & 0.01 & 0.05 & - & 0.05 & - & - & - \\
\hline Haptoglobin & 0.05 & 0.01 & 0.01 & - & - & - & 0.05 & - \\
\hline GGTP & - & - & 0.05 & - & - & 0.05 & 0.05 & - \\
\hline WBC & - & 0.05 & 0.05 & - & - & - & - & - \\
\hline Fibrinogen & - & 0.05 & 0.01 & - & - & - & 一 & - \\
\hline SGOT & - & - & - & - & 0.05 & - & - & - \\
\hline Platelet count & - & - & - & 一 & 0.05 & - & 一 & - \\
\hline Bilirubin & - & - & - & - & - & - & - & - \\
\hline Creatinine & - & - & - & - & - & 一 & - & - \\
\hline Globulin & 一 & - & - & - & - & - & - & - \\
\hline Protein & - & - & - & - & - & - & - & - \\
\hline Sulphydryl & - & 一 & 一 & - & - & - & 一 & - \\
\hline Histidine & - & - & - & - & - & - & - & 一 \\
\hline $\mathrm{Hb}$ & - & - & - & - & - & 一 & 一 & 一 \\
\hline \multicolumn{9}{|c|}{ B. Sodium aurothiomalate } \\
\hline Histidine & 0.05 & 0.001 & 0.001 & 0.01 & 0.01 & 0.01 & 0.01 & 0.05 \\
\hline CRP & 0.001 & 0.05 & 0.001 & 0.001 & 0.001 & 0.001 & 0.01 & - \\
\hline Sulphydryl & 0.01 & 0.05 & 0.001 & 0.001 & 0.01 & 0.01 & 0.001 & - \\
\hline Plasma viscosity & 0.01 & 0.05 & 0.001 & 0.01 & 0.001 & 0.001 & 0.01 & - \\
\hline ESR & 0.01 & 0.01 & 0.001 & 0.05 & 0.01 & 0.001 & 0.01 & - \\
\hline Haptoglobin & 0.01 & 0.05 & 0.01 & 0.01 & 0.001 & 0.001 & 0.01 & - \\
\hline Proteins & 0.01 & 0.05 & 0.01 & 0.05 & 0.01 & 0.001 & 0.05 & - \\
\hline $\mathrm{Hb}$ & 0.05 & 0.01 & 0.01 & 0.05 & 0.05 & 0.05 & 0.05 & 0.05 \\
\hline Globulin & 0.05 & - & 0.05 & 0.05 & 0.01 & 0.001 & 0.05 & 一 \\
\hline Fibrinogen & 0.05 & - & 0.05 & - & 0.05 & 0.05 & - & - \\
\hline WBC & - & - & - & - & - & - & - & 0.05 \\
\hline Creatinine & - & - & - & - & - & - & - & 0.05 \\
\hline Platelet count & - & - & - & - & 0.05 & 0.05 & - & - \\
\hline GGTP & - & - & - & - & - & - & - & 0.05 \\
\hline Alkaline phosphatase & - & - & - & - & - & - & - & - \\
\hline SGOT & 一 & - & 一 & - & - & - & - & - \\
\hline Albumin & - & - & - & - & - & - & - & 一 \\
\hline Bilirubin & - & - & 一 & - & - & - & - & - \\
\hline
\end{tabular}

GGTP = gamma glutamyl transpeptidase. 
Table 2 One-way analyses of variance to determine the degree of matching between week 0 data for each parameter shown in Figs. 1 and 2 for the 2 drug treatment groups

\begin{tabular}{|c|c|c|c|c|c|c|}
\hline \multirow[t]{2}{*}{ Measurement } & \multicolumn{2}{|l|}{$H C Q$} & \multicolumn{2}{|l|}{ Gold } & \multirow[t]{2}{*}{$F$} & \multirow[t]{2}{*}{$P<$} \\
\hline & Mean & $\pm S D$ & Mean & $\pm S D$ & & \\
\hline Articular index & 21 & 13 & 24 & 13 & 0.33 & NS \\
\hline Pain score & $2 \cdot 7$ & 0.6 & $3 \cdot 1$ & $1 \cdot 0$ & $1 \cdot 47$ & NS \\
\hline Early morning stiffness (min) & 163 & 186 & 252 & 271 & 0.95 & NS \\
\hline Summated change score & 0 & 0 & 0 & 0 & 0.00 & NS \\
\hline ESR (mm. h-1) & 49 & 22 & 53 & 21 & $0 \cdot 22$ & NS \\
\hline Haptoglobin (g. $\left.1^{-1}\right)$ & $4 \cdot 55$ & $1 \cdot 51$ & $5 \cdot 14$ & $1 \cdot 30$ & $1 \cdot 16$ & NS \\
\hline CRP (mg. dl-1) & 2.60 & $2 \cdot 13$ & $4 \cdot 57$ & $3 \cdot 36$ & $3 \cdot 18$ & NS \\
\hline Fibrinogen (g.1-1) & $3 \cdot 3$ & 0.7 & $3 \cdot 3$ & 0.7 & 0.03 & NS \\
\hline Total protein $\left(\mathrm{g} .1^{-1}\right)$ & $76 \cdot 1$ & 3.9 & $76 \cdot 8$ & $4 \cdot 9$ & $0 \cdot 18$ & NS \\
\hline Globulin (g.1-1) & 34 & 3 & 37 & 4 & $4 \cdot 73$ & 0.05 \\
\hline Haemoglobin (g.dl-1) & $11 \cdot 8$ & $1 \cdot 6$ & $11 \cdot 8$ & $1 \cdot 2$ & $<0.01$ & NS \\
\hline White cell count $\left(x 10^{9}-1\right)$ & $8 \cdot 3$ & 1.9 & $8 \cdot 5$ & $2 \cdot 0$ & 0.06 & NS \\
\hline Platelet count $\left(\times 10^{9} 1^{-1}\right)$ & 359 & 108 & 371 & 138 & 0.06 & NS \\
\hline Total serum sulphydryl $\left(\mu \mathrm{mol} .1^{-1}\right)$ & 399 & 52 & 377 & 58 & 1.06 & NS \\
\hline
\end{tabular}

$\mathrm{SD}=$ standard deviation. $\mathrm{NS}=$ not significant.

11 were considered to have shown clinical improvement; 2 showed deterioration in all clinical variables measured. All side effects were minor, and there was no retinal damage over the 6-month treatment period.

There was notable improvement in clinical variables by week 12 , accompanied by a significant reduction in the acute-phase proteins and plasma viscosity. A downward trend was observed in the erythrocyte sedimentation rate (ESR), though this was not statistically significant. Mean data for clinical and biochemical variables showing a change during treatment are presented graphically (Figs. 1 and 2).

\section{SODIUM A UROTHIOMALATE THERAPY}

Thirteen of the 15 patients entered were considered to show clinical improvement; 1 defaulted from the clinic at week 4 and another withdrew with a rash at week 12. Improvement was seen by week 16 as reflected by statistically significant changes in the mean data for clinical variables (Fig. 1) and the acute-phase proteins, ESR, plasma viscosity, serum sulphydryl, serum histidine, globulin, and total protein (Fig. 2). In addition a statistically significant reduction in mean white cell count from baseline values was observed, though in no individual did this necessitate any change in therapeutic regimen. Five patients showed a steady fall in platelet count, also within the normal range, though there was no significant reduction in mean data.

\section{STATISTICAL ASSESSMENTS}

Correlation matrices for both HCQ and gold therapy are shown in Table 1A and B respectively. In each matrix the biochemical variables are shown in ranking order, those at the top correlating better with the clinical variables than those at the bottom for that particular drug. Significant correlations were demonstrated between a large number of clinical and laboratory variables as denoted by $p$ levels of less than 0.05 . This was particularly noticeable in the gold-treated group, where core relations were in general stronger and more numerous.

The 2 treatment groups were seen to be we matched at week 0 (Table 2), with only globulin showing a significant difference.

\section{Discussion}

The use of serum biochemical changes in defining antirheumatoid drug efficacy has been previously established. ${ }^{17}$ In terms of the acute-phase proteins, ESR, and plasma viscosity, HCQ produced a later (as defined by the time of significant change in $\dot{0}$ serum biochemistry) and less marked change than did gold or D-penicillamine. ${ }^{2}$ This suggests that $ᄋ$ HCQ, despite its confirmed efficacy in controlled $₹$ studies in the treatment of $\mathrm{RA},{ }^{89}$ is nevertheless $ᄋ$ less effective than the more established antirheu- $D$ matoid drugs. The particular value of plasma viscosity in the management of patients receiving $N$ hydroxychloroquine is discussed elsewhere. ${ }^{10}$

This finding is substantiated in terms of the $\tilde{O}$ correlation matrices constructed between clinical and biochemical variables. Correlations were fewer and weaker for HCQ than for both gold and o D-penicillamine. ${ }^{1}$ Each matrix was constructed from $\underset{\complement}{\complement}$ 144 Pearson correlations each based on 8 data pairs. $\stackrel{\oplus}{+}$ Hence one can expect 7 falsely significant correlations $T$ at $p<0.05(1$ in 20) to arise by chance. There were in $\stackrel{\vec{P}}{\circ}$ fact 19 correlations of $p<0.05$ in the HCQ matrix $\stackrel{\mathbb{Q}}{\stackrel{Q}{Q}}$ and 24 in the gold matrix, so about one-third of all $\stackrel{\otimes}{\stackrel{\otimes}{Q}}$ 
these correlations at $p<0.05$ were falsely significant. However, this does not detract from our overall finding that the greater improvement in the biochemical and clinical variables for gold-treated patients gave rise to a larger number of significant correlations.

While the acute-phase proteins, ESR, and plasma viscosity ${ }^{10}$ have been shown to be non-specific indices of disease improvement, some biochemical variables showed changes which were more specific. For example, serum histidine failed to improve with HCQ therapy ${ }^{11}$ but, in contrast to a previous report, ${ }^{12}$ showed an upward trend with gold therapy. Haemoglobin levels rose towards normal with gold and D-penicillamine ${ }^{1}$ but, in agreement with previous work ${ }^{9}$ and in contrast to others, ${ }^{8}$ remained unchanged with HCQ. The total serum sulphydryl level improved for gold and D-penicillamine. ${ }^{13}$ While this could be attributed to the sulphydryl groups that form part of the structure of these two drugs, we favour an indirect change consequent upon the therapeutic action of these drugs or a combination of both of these as the reason for increased total serum sulphydryl. HCQ's failure to increase serum sulphydryl levels may reflect the drug's weaker activity rather than the lack of sulphydryl group in its structure.

In this parallel group study the analysis showed that week 0 data were essentially matched between the 2 groups, and hence differences in the response of serum histidine, haemoglobin, and serum sulphydryl levels following HCQ therapy compared with gold would suggest a different mode of action of this drug. The failure of total serum sulphydryl, haemoglobin, and histidine levels to improve with HCQ therapy is reflected by the lack of significant correlation between these measurements and the clinical variables.

For the gold-treated patients a temporary rise in the acute-phase reactants was observed at week 2 with the exception of $\mathrm{C}$-reactive protein. This rise achieved statistical significance in the case of ESR $(p<0 \cdot 05)$. This slight deterioration in biochemical status was also reflected by some other variables such as protein and platelet count, suggesting a genuine initial adverse metabolic reaction to the presence of gold which is rapidly masked by improvement in the disease state. This adds scientific support to the anecdotal clinical impression that some patients experience an initial exacerbation of symptoms on starting gold injections.

Although we favour the greater efficacy of gold as the main explanation for the conflicting results obtained between gold and HCQ, 2 other explanations should be considered. The therapeutic effect may be dose-dependent, and the dose selected is therefore important in determining results. $\mathrm{HCQ}$ might have performed better had we chosen a higher dose than $400 \mathrm{mg} /$ day, though this might have caused a higher risk of ocular side effects. Inequality of patient groups must also be considered in a nonrandomised study. All patients conformed to identical admission criteria and were drawn from the same patient pool, the study being completed within 1 year. We think it unlikely the nature of rheumatoid disease would alter in this short period, and the failure to show a significant difference between patient groups on entry makes a seasonal bias unlikely. Assay of biochemical standards at regular intervals excluded anomalies due to laboratory reagents or technique, and variation in clinical assessment, perhaps the greatest potential source of error, was minimised by intermittent tests of interobserver error between the 2 participating metrologists.

Our findings in this human test system, akin to the testing of drugs at an early stage of their development in an animal model, suggest that HCQ occupies an intermediate position between the more effective drugs, such as gold and D-penicillamine, ${ }^{2}$ and weaker drugs, such as alclofenac ${ }^{2}$ and aspirin. ${ }^{14}$ Controlled clinical trials confirm this ranking order of effectiveness, lending credence to our human test system as a method for detecting antirheumatoid activity in novel compounds.

The authors thank Mrs P. A. Leatham and Mrs V. M. Rhind for the clinical assessments; Mr J. R. Lowe for expert technical assistance; and Mrs D. K. Smith for secretarial assistance.

The Clinical Pharmacology Unit gratefully acknowledges the financial support of Roche Products Ltd.

\section{References}

1 Dixon J S, Pickup M E, Lowe J R, Hallett C, Lee M R, Wright V. Discriminatory indices of response of patients with rheumatoid arthritis treated with D-penicillamine. Ann Rheum Dis 1980; 39: 301-11.

2 Bird H A, Dixon J S, Pickup M E, Lee M R, Wright V. A biochemical comparison of alclofenac and D-penicillamine in rheumatoid arthritis. Ann Rheum Dis 1980; 39: $281-4$.

3 Rothermich N O. Chloroquine in rheumatoid arthritis. Ann Intern Med 1965; 62: 1065-6.

4 Mackenzie A H. An appraisal of chloroquine. Arthritis Rheum 1970; 13: 280-91.

5 Marks J S, Power B J. Is chloroquine obsolete in treatment of rheumatic disease? Lancet $1979 ; \mathbf{i}$ : 371-3.

- Siegel S. Non-parametric Statistics for the Behavioural Sciences. New York: McGraw-Hill, 1956: 75.

7 McConkey B, Crockson R A, Crockson A P, Wilkinson A R. The effects of some anti-inflammatory drugs on the acute phase proteins in rheumatoid arthritis. $Q \mathrm{~J} \mathrm{Med}$ 1973; 42: 785-91.

8 Mainland D, Sutcliffe M I. Hydroxychloroquine sulphate 
in rheumatoid arthritis, a six month double-blind trial. Bull Rheum Dis 1962; 8: 287-90.

- Hamilton E B D, Scott J T. Hydroxychloroquine sulphate (Plaquenil) in treatment of rheumatoid arthritis. Arthritis Rheum 1962;5: 502-12.

10 Pickup M E, Dixon J S, Bird H A, Wright V. Plasma viscosity as an index of disease activity in rheumatoid arthritis. Ann Rheum Dis 1981 ; in press.

11 Pickup M E, Dixon J S, Lowe J R, Wright V. Serum histidine in rheumatoid arthritis: changes induced by anti-rheumatic drug therapy. $J$ Rheumatol $1980 ; 7: 71-6$

12 Gerber D A. Anti-rheumatic drugs, the ESR, and the hypohistidinemia of rheumatoid arthritis. $J$ Rheumatol 1977; 4: 40-5.

13 Pickup M E, Dixon J S, Bird H A. On the effects of anti-rheumatic drugs on protein sulphydryl reactivity in human serum. J Pharm Pharmacol 1980; 32 : 301-2.

14 Bird H A, Rhind V, Leatham P, Saunders A, Wright V Enteric coated aspirin in rheumatoid arthritis. Rheumato Rehabil 1981 ; in press. 